\title{
An investigation on the role of learning organization in the realization of organizational learning based Marquart model: A case study of Islamic Azad University, Neyshabur branch
}

\author{
Ahmad Nategh Golestan* and Seyed Morteza Ghayour Baghbani
}

Department of Management, Neyshabur branch, Islamic Azad University, Neyshabur, Iran

\section{CHRON I C LE ABSTRACT}

Article history:

Received June 28, 2013

Received in revised format

19 October 2013

Accepted 20 December 2013

Available online

January 22014

Keywords:

Learning organization

Organizational learning

Marquardt model

Islamic Azad University

\begin{abstract}
During the past few years, there has been increasing interest in identifying the strengths and weaknesses of learning organizations (LO) in universities. The theoretical basis of this study was based on a comprehensive and systematic approach to learning organization proposed by Michael Marquardt. The aim of this study was to evaluate the benefit of Islamic Azad University, Neyshabur branch as educational characteristics in terms of LO characteristics according to the science and technology dimensions. The study population included all faculty members of Islamic Azad University Neyshabur branch, 90 university professors were selected by simple random sampling, and they completed the questionnaires of the survey. The research instruments included a researcher-made questionnaire based on the Marquardt-reviewed literature and consultation with experts. The questionnaire included 50 items with a Likert scale of five degrees. Validity of the questionnaire was affirmed by calculating Cronbach's alpha coefficient. To test the hypothesis, paired t-student tests were used and the results indicated that the status of Islamic Azad University in terms of LO characteristics was significantly different from the desirable level.
\end{abstract}

\section{Introduction}

An organization applies information strategically in three purposes such as to make sense of change in its environment; to build new knowledge for innovation; and to make necessary decisions about necessary actions. These distinct processes are complementary pieces of a bigger canvas, and the information behaviors analyzed in each part interweave into a better explanation of information implementation in different firms. Most employees in organizations give meaning to the events and actions of the firms. Through knowledge creation, the insights of individuals are changed into knowledge, which could be applied to design new products or improve performance. In decision making, understanding and knowledge are normally concentrated on the choosing of an appropriate

\footnotetext{
*Corresponding author. Tel: +98-09125575009

E-mail addresses: a.nateq@gmail.com (A. Nategh Golestan) 
course of action. By holistically managing its sense making, knowledge creation and decisionmaking processes, the Learning Organization (LO) plays essential role on understanding and knowledge to act wisely and decisively (Choo, 1996; Garvin, 2000). Gephart (1996) described LOs and described essential features, training and trainers, outcomes, and types of leaders. Real et al. (2006) evaluated the role played by information technology (IT) in organizational learning (OL) considered as a kind of process of knowledge creation and detected by the interaction of stocks and flows variables. They performed an investigation on how IT and OL impact both business performance and the development of the technological distinctive competencies (TDCs). These relationships were examined via an empirical analysis carried out with a sample of 140 industrial firms and their findings confirmed that IT could act as an enabler of the OL process and influenced on the development of TDCs, which permitted the achievement of a better business performance. Such competencies were also the result of OL, thus explaining the influences of them both on perceived organizational performance.

Yang et al. (2004) explained various efforts on development and validation a multidimensional measure of the LO by developing an instrument based on a critical review of both the conceptualization and practice of this construct. Discussions of LO often ends up intangible and obscure while OL is easy to recognize, it is often difficult to explain and dissect. Wick and Leon (1995) offered a solid strategy for building a LO and their extensive research recommended that at least five elements were essential for firms to become LOs. Together, these elements provided an approach for building a LO and by closely investigating each element within that method, managers may measure and increase the rate of learning within their organizations.

\section{The proposed model}

This paper evaluates the benefit of Islamic Azad University, Neyshabur branch as educational characteristics in terms of LO characteristics according to the science and technology dimensions. The study population included all faculty members of Islamic Azad University Neyshabur branch, 90 university professors are selected by simple random sampling, and they completed the questionnaires of the survey. The research instruments included a researcher-made questionnaire based on the Marquardt-reviewed literature (Marquardt, 1996, 2002) and consultation with experts. Fig. 1 demonstrates the structure of the proposed study.

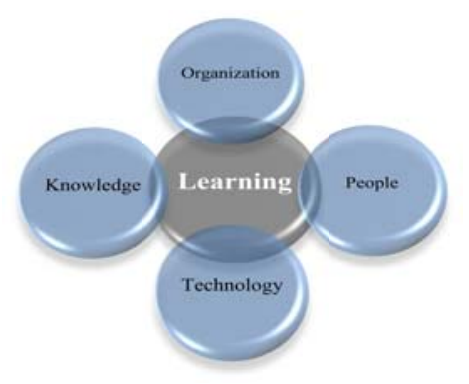

Fig. 1. The framework of Marquardt approach

The following are the core characteristics of Knowledge and Technology subsystems comprising Marquardt’s (2002) systems learning organizational model : 
Knowledge subsystem: Marquardt defined knowledge as a collection of information, principles and experiences that actively considers the implementation, management, decision-making and guide problem-solving.

Technology subsystem: Subsystem technology includes integrated networking technologies and information tools, which enables access and exchange of information and learning. This subsystem incorporates technical processes, systems and structures for collaboration, coaching, coordination and other knowledgeable skills. In addition, this subsystem includes electronic instruments and advanced techniques such as conferences, computer simulation and computer-based collaboration. Therefore, the main objective of this research is to describe these sub-systems and to study Islamic Azad University, Neyshabur branch enjoyment of learning organizations in both subsystem characteristics and knowledge management technology.

The purpose of this study is to explore and to describe the LO profile of Islamic Azad University, Neyshabur branch (IAUN). We are also interested in studying factors accounted for variation among the LO profile. The learning organization profile and selected demographic characteristics are analyzed in order to establish a profile of IAUN. The following hypotheses are considered for the proposed study of this paper,

$\mathrm{H}_{1}$ : There is a significant difference between present and effective situation of IAUN in characteristics of learning organization, in terms of the knowledge management from the point of view of faculty members.

$\mathrm{H}_{2}$ : There is a significant difference between present and effective situation of IAUN in characteristics of learning organization, in the technology management from the point of view of faculty members.

This research is descriptive and survey study in terms of the objective, cross-sectional study in terms of the time, applying in terms of the results, inductive in terms of the study of logic and quantitative in terms of the research process. Research's subject scope has been around excellence and learning paradigms, spatial scope has been IAUN and research time scope was in 2013. Study population has been officials and employees of the university with a total number of 324 patients. Therefore, the sample size is calculated as follows,

$$
n=\frac{N \times z_{\alpha / 2}^{2} \times p \times q}{\varepsilon^{2} \times(N-1)+z_{\alpha / 2}^{2} \times p \times q},
$$

where $N$ is the population size, $p=1-q$ represents the yes/no categories, $z_{\alpha / 2}$ is CDF of normal distribution and finally $\varepsilon$ is the error term. Since we have $p=0.5, z_{\alpha / 2}=1.96$ and $N=324$, the number of sample size is calculated as $n=78$. Sampling method has been stratified random sampling. Data collection tool, has been researcher mode's questionnaire entitled evaluation of organizational learning mechanisms based on five liker scale.

The instrument used in data collection was adapted from an instrument called Learning Organization Profile (LOP), developed by Marquardt (1996) to assess the level of organizational learning in two of five main organizational systems: (a) organization, (b) knowledge, (c) learning, (d) technology, and (e) people. The LOP questionnaire contains statements related to organizational learning pertaining to either public or private organizations. The perception of IAUN extension personnel as a learning organization will be calculated using a mean score on a 50-item, five-point, Likert-type measurement instrument. Each item is rated from 1 (strongly disagree) to 5 (strongly agree). The questionnaire consisted of 50 items. It assessed how distributed component based on the characteristics of respondents to the questionnaire as each of the components of information acquisition and 
information creation, information application, data mining, information transfer and information storage, and distribution of technology is used by 5 items and components development learning and information management technology is used is measured by 10 items. Content and face validity were established through a panel of experts and a field test, respectively. For the LOP questionnaire pertaining to statements about the learning organization profile using a Likert-type scale of measurement, a coefficient of internal consistency using Cronbach's alpha methodology was also calculated. The reliability coefficient for the questionnaire was .90 , a value considered to be representative of a reliable instrument.

Data were analyzed by the SPSS Base 8.0 (1999) computer program. Descriptive statistics including means, medians, modes, standard deviations, ranges, frequencies, and percentages were calculated for objectives. An analysis of variance was performed for testing differences among demographic groups on the variable dominant culture type (actual and preferred situations). A t-test for means difference between sex and dominant culture type was also performed.

\section{The results}

Techniques of descriptive and deductive statistics have been used to analyze data. To test hypotheses; t-test one sample and independent samples test techniques with SPSS software applied. Specifications of statistical samples are the questionnaire indicated that $26 \%$ of faculties are women and $74 \%$ are men. also 31\% have the highest frequency and 66\% of staff have Bachelor's degree, (B.A) and 3\% are Tuition.

The test of research's first hypothesis is shown in the Table 1.

$\mathrm{H}_{1}$ : There is a significant difference between present and effective situation of IAUN in terms of of learning organization, in the knowledge management.

$\mathrm{H}_{0}$ : There is not any significant difference between present and effective situation of IAUN in terms of learning organization, in the knowledge management.

$\mathrm{H}_{1}$ : There is a significant difference between present and effective situation of IAUN in terms of learning organization, in the technology management.

$\mathrm{H}_{0}$ : There is not any significant difference between present and effective situation of IAUN in terms of learning organization, in the technology management.

\section{Table 1}

Evaluate significant difference between present and effective situation of knowledge and technology subsystems

\begin{tabular}{|c|c|c|c|c|c|c|c|c|c|}
\hline \multirow{2}{*}{ Description } & & \multirow[b]{2}{*}{ number } & \multirow[b]{2}{*}{ mean } & \multirow{2}{*}{ Std.Error } & \multirow{2}{*}{$\begin{array}{c}\text { Mean } \\
\text { Difference }\end{array}$} & Estimated & \multirow{2}{*}{ df } & \multirow{2}{*}{$\begin{array}{c}\text { Sig } \\
\text { (2-Tailed }\end{array}$} & \multirow{2}{*}{ Result } \\
\hline & & & & & & t-student & & & \\
\hline \multirow{2}{*}{ Collection of outside information } & Present & 90 & 11.23 & 3.16 & \multirow{2}{*}{9.13} & \multirow{2}{*}{21.033} & \multirow{2}{*}{89} & \multirow{2}{*}{0.000} & \multirow{2}{*}{ Accepted } \\
\hline & Effective & 90 & 20.36 & 2.57 & & & & & \\
\hline \multirow{2}{*}{ Creation (new knowledge) } & Present & 90 & 12.73 & 3.25 & \multirow{2}{*}{8.06} & \multirow{2}{*}{18.006} & \multirow{2}{*}{89} & 0.000 & \multirow{2}{*}{ Accepted } \\
\hline & Effective & 90 & 20.8 & 2.71 & & & & & \\
\hline \multirow{2}{*}{ Utilization } & Present & 90 & 11.5 & 3.16 & \multirow{2}{*}{8.76} & \multirow{2}{*}{20.39} & \multirow{2}{*}{89} & 0.000 & \multirow{2}{*}{ Accepted } \\
\hline & Effective & 90 & 20.26 & 2.57 & & & & & \\
\hline \multirow{2}{*}{ Data mining } & Present & 90 & 11.23 & 3.16 & \multirow{2}{*}{9.13} & \multirow{2}{*}{21.033} & \multirow{2}{*}{89} & 0.000 & \multirow{2}{*}{ Accepted } \\
\hline & Effective & 90 & 20.36 & 2.57 & & & & & \\
\hline \multirow{2}{*}{$\begin{array}{l}\text { Storage (coding and preserving } \\
\text { information) }\end{array}$} & Present & 90 & 13 & 3.44 & \multirow{2}{*}{7.36} & \multirow{2}{*}{14.71} & \multirow{2}{*}{89} & 0.000 & \multirow{2}{*}{ Accepted } \\
\hline & Effective & 90 & 20.36 & 3.53 & & & & & \\
\hline \multirow{2}{*}{ Transfer (information movement) } & Present & 90 & 12.46 & 3.37 & 796 & 1905 & 89 & 0.000 & Accented \\
\hline & Effective & 90 & 20.43 & 2.92 & 1.00 & 15.00 & 03 & & Hссерте \\
\hline The uce of technology in learning & Present & 90 & 40.86 & 5.51 & & & & 0.000 & \\
\hline 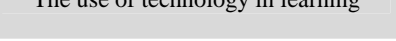 & Effective & 90 & 26.86 & 6.11 & 14 & 17.82 & 89 & & Accepted \\
\hline Application of knowledge management & Present & 90 & 23.36 & 5.67 & 161 & 2064 & 89 & 0.000 & Accented \\
\hline technology & Effective & 90 & 39.5 & 6.29 & 10.1 & 20.04 & 03 & & Hсcepted \\
\hline
\end{tabular}


Table 2 summarizes the results of testing the difference between present and desirable situation in terms of knowledge subsystem.

\section{Table 2}

Evaluate significant difference between present and effective situation of knowledge subsystems

\begin{tabular}{ccccccccccc}
\hline Description & State & No & Mean & Std. dev. & & t-value & df & Sig. & Result \\
\hline \multirow{2}{*}{ Knowledge Management } & Present & 90 & 72.8 & 18.21 & & \multirow{2}{*}{4.8} & 19.78 & 89 & 0.00 & Approved \\
\cline { 2 - 9 } & desirable & 90 & 120.83 & 19.2 & & & & &
\end{tabular}

Since estimated t-student is larger than critical value with 95\% confidence level (1.96), $\mathrm{H}_{0}$ is rejected and alternative hypothesis is approved. Therefore, the characteristics of knowledge subsystems of learning organization are not in desirable level in IAUN. In addition, Table 3 examines the second hypotheses for the difference between the present and ideal circumstances of technology subsystems.

\section{Table 3}

Evaluate significant difference between present and effective situation of technology subsystems

\begin{tabular}{|c|c|c|c|c|c|c|c|c|c|}
\hline Description & State & No & Mean & Std. dev. & & t-value & $\mathrm{df}$ & Sig. & Result \\
\hline Tochnology & Present & 90 & 50.23 & 10.17 & \multirow{2}{*}{30.1} & \multirow{2}{*}{20.07} & \multirow{2}{*}{89} & \multirow{2}{*}{0.000} & \multirow{2}{*}{ Accepted } \\
\hline 1 естा1010gy & effective & 90 & 80.36 & 12.01 & & & & & \\
\hline
\end{tabular}

Since estimated $t$ is larger than critical value of $t$ (1.96) with 95\% confidence level, $\mathrm{H}_{0}$ is rejected and alternative hypothesis is approved so, the characteristics of technology subsystems of learning organization are not in desirable level in IAUN. The mean rank test of significance using the Friedman test revealed a significant difference in ranking them. These scores indicate that the component of knowledge acquisition and knowledge transfer and application of technology in the learning and application of technology in knowledge management as well as the state of the university are below average.

\section{Table 4}

Comparing the average of the sub-systems of knowledge management

\begin{tabular}{clc}
\hline Row & Item & Mean \\
\hline 1 & Collection of outside information & 2.85 \\
2 & Creation (new knowledge) & 2.98 \\
3 & Utilization & 3.08 \\
4 & Data mining & 3.73 \\
5 & Storage (coding and preserving information) & 3.88 \\
6 & Transfer (information movement) & 4.47 \\
\hline
\end{tabular}

Moreover, Friedman test has been performed to rank different factors and it indicates that “Application of knowledge management technology” maintains a mean ranking of 2.63 followed by "The use of technology in learning” with the mean rank of 2.05.

\section{Discussion and conclusion}

This paper has evaluated the benefit of Islamic Azad University, Neyshabur branch as educational characteristics in terms of LO characteristics according to the science and technology dimensions. Based on our survey the university could not acquire necessary knowledge of the internal environment and its external environment to deal with weaknesses in knowledge acquisition performance. In the process of knowledge creation, existing infrastructure has failed to encourage 
teachers, students and the general body of scientific knowledge and to create knowledge. In addition, knowledge in this university (e.g. projects and research projects and dissertations, etc.) used in place are not well and only after completion of the plans and projects. They have archived and knowledge is not the basis for management decisions. On the other hand, the absence of regular structure analysis and data mining of existing knowledge have led the university managers to fail for data mining as an analytic tool for empowerment in order to find the meaning of existing data and knowledge to use. Thus, managers cannot provide the information to help develop strategies and present complex questions, store and extract.

The results also indicate that the transfer and sharing of knowledge in the university are not good. One university transportation capacity for knowledge shows transfer and sharing of expressive power, which indicates the successful of firms. Knowledge accurately and quickly must be distributed around universities or colleges and departments, in order to lead the University towards changing the university into a learning organization. In terms of storage component of knowledge, we must also say that the status of the University was not capable of maintaining the present status of knowledge created in organizations. Procedures and structures for the maintenance of existing knowledge into the design and creation of assets are not sufficient. In general, it can be stated that if the university plans to move towards becoming a learning organization, it should improve its oprations in two dimensions, knowledge management and technology structures.

\section{References}

Choo, C. W. (1996). The knowing organization: how organizations use information to construct meaning, create knowledge and make decisions. International Journal of Information Management, 16(5), 329-340.

Garvin, D. A. (2000). Learning in Action: A Guide to Putting the Learning Organization to Work. Harvard Business Press.

Gephart, M. A. (1996). Learning Organizations Come Alive. Training and Development, 50(12), 3445.

Marquardt, M. J. (1996). Building the learning organization: A systems approach to quantum improvement and global success. New York: McGraw-Hill.

Marquardt, M. J. (2002). Building the learning organization: mastering the 5 elements for corporate learning. Nicholas Brealey Publishing.

Real, J. C., Leal, A., \& Roldán, J. L. (2006). Information technology as a determinant of organizational learning and technological distinctive competencies. Industrial Marketing Management, 35(4), 505-521.

Yang, B., Watkins, K. E., \& Marsick, V. J. (2004). The construct of the learning organization: Dimensions, measurement, and validation. Human Resource Development Quarterly, 15(1), 3155.

Wick, C. W., \& Leon, L. S. (1995). From ideas to action: Creating a learning organization. Human Resource Management, 34(2), 299-311. 